\title{
Operational Requirements of Unmanned Aircraft Systems Data Link and Communication Systems
}

\author{
Hüseyin Okcu
}

\begin{abstract}
Unmanned Aircraft System (UAS) communication and data links should have special requirements considering military concept of operations in order to fulfill operations successfully and safely. This paper reviews the military operational requirements of the UAS data link and communication systems for conceptual design phase of UAS. Military operational use of UAS introduced special requirements such as interoperability, robustness to jamming and deceptions, Low Probability of Intercept (LPI) etc. In this context, operational design requirements of UAS data link and communication systems are investigated in detail.
\end{abstract}

Index Terms-Unmanned aircraft systems, line-of-sight operations, ground control station, interoperability, low probability of intercept.

\section{INTRODUCTION}

Unmanned Aircraft Systems (UAS) composed of many subsystems. These subsystems are classified as avionics, propulsion, communication and data link systems, recovery and payloads in generally. Each subsystem is crucial for the success of the UAS operations and to be designed peculiarly compatible with unmanned design structure. In this context, UAS communication and data link systems are subsystems that provide unmanned flight capability with the ability of remote control and data acquisition. Remote control and data acquisition ability requires some special requirements for the design process.

UAS data link and communication systems have mission-critical tasks such as supporting the command and control (C2) of the Unmanned Aircrafts (UAs) and payloads, maintaining the Network Centric infrastructure, relaying signals to the other UAs and transferring the intelligence data (radar targets, synthetic video, laser designation etc.) gathered from payloads. For this reason, continuous maintenance of data link and communication is crucial for the UAS. Therefore, in order to benefit from wide capability of an UAS, communication losses result from;

- Failure,

- Geographic obstacles,

- Weakening of received power,

- Jamming

should be minimized. In addition to maintenance of links; high data rate and available bandwidth requirements are also very important for UAS operations [1].

It has vital importance to define requirements in especially software-intense defense system projects at the very beginning of the projects. In Table I, system acquisition and

Manuscript received September 29, 2015; revised January 26, 2016.

H. Okcu is with the Turkish Naval War College, İstanbul, Turkey (e-mail: huseyinokcu@outlook.com). life cycle has been depicted. Defining requirements process is conducted in the "Conceptual Design", the first phase of the project life cycle. Any fault or lack in the requirements will make the ongoing system acquisition and life cycle process more difficult for users, other production and maintenance teams. As a matter of fact, any critical fault can hinder the success of the project. As the success of fulfilling the military operational task is very critical, requirements have to be defined without any short and fault.

Consequently, as UAS data link and communication system is both a defense and software and electronic intense system, requirement defining, performed in this paper, is very important on the success of the UAS projects. In this context, in the following sections of the paper, operational requirements of these systems will be explained in detail.

TABLE I: SYSTEM ACQUISITION AND LIFE CYCLE PROCESS [2]

\begin{tabular}{|c|c|c|c|c|c|}
\hline $\begin{array}{l}\text { Conceptual } \\
\text { Design }\end{array}$ & $\begin{array}{l}\text { Preliminary } \\
\text { Design }\end{array}$ & $\begin{array}{l}\text { Detailed } \\
\text { Design and } \\
\text { Development }\end{array}$ & $\begin{array}{l}\text { Production/ } \\
\text { Construction }\end{array}$ & $\begin{array}{l}\text { Operational Use } \\
\text { and System } \\
\text { Support } \\
\end{array}$ & Retirement \\
\hline $\begin{array}{l}\text { System } \\
\text { Level }\end{array}$ & $\begin{array}{l}\text { Subsystem } \\
\text { Level }\end{array}$ & $\begin{array}{l}\text { Component } \\
\text { Level }\end{array}$ & $\begin{array}{l}\text { Modification for } \\
\text { Improvement }\end{array}$ & $\begin{array}{l}\text { Modification for } \\
\text { Improvement }\end{array}$ & - \\
\hline
\end{tabular}

\section{UAS CONCEPTS OF OPERATIONS CONSIDERING DATA LINK SYSTEMS}

Main parts of the UAS related to data link and communication systems are Ground Control Station (GCS), Air Data Terminal (ADT) embedded on UA and antennas. Additionally, satellite systems are deployed on UAs in order to fulfill beyond Line-Of-Sight (LOS) tasks with the use of satellite communication (SATCOM) [3], [4].

LOS and beyond LOS (BLOS) operations are the current Concept of Operations (CONOPS) of the UAs related to communication and data link systems. In case of LOS communication, antennas on both UAs and GCS must be in the range of LOS. As for BLOS operations, communication is performed via relay UA or SATCOM whereby UA can be used in long ranges as depicted in Fig. 1. In the LOS operations all kind aircrafts can be deployed, on the other hand, only medium and high altitude and long endurance aircrafts (MALE and HALE) are available to conduct BLOS operations [5].

BLOS operation requires UAS to have ability to relay communication and data link signals to the distant aircraft or communicate with satellites. In addition to UA, GCS must also have connection capability with satellites in order to execute SATCOM BLOS operation in the long distances. On the other hand, LOS operation is performed in short distances. However, there is another way of extending operation range in the LOS operations: handover method as shown in Fig. 2. In this method additional GCS's are deployed in the operation field for taking control of UAs in their LOS 
coverage so that UAs can operate in long distances with LOS communications.

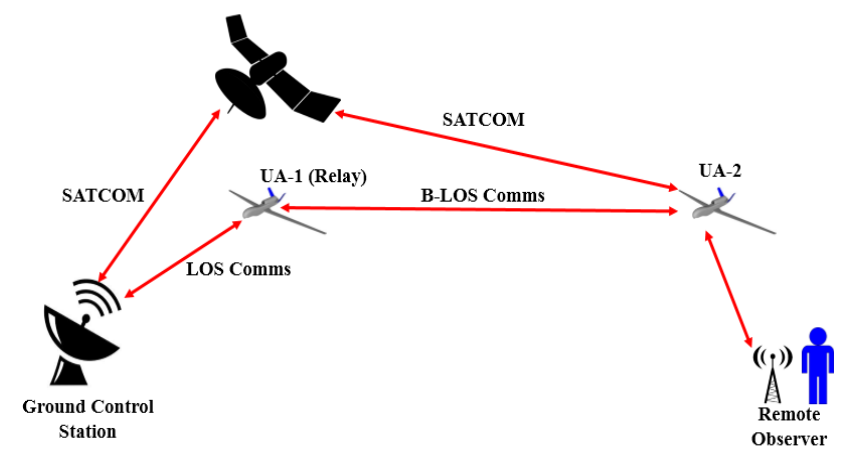

Fig. 1. Communication topology of LOS and BLOS operations.

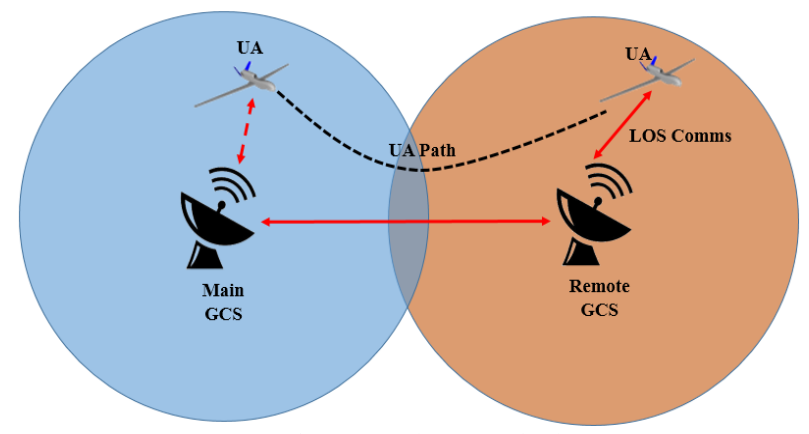

Fig. 2. Handover method.

UAS must have various radio channels in order to meet both technical and legal issues. As a technical requirement, command control and telemetry data link has vital significance to provide safe flight. Therefore, this channel had been better to be backed up. As a legal issue, it is mandatory follow Air Traffic Control (ATC) radio channels for the purpose of conducting safe flights as well as meeting the standards determined by the International Civil Aviation Organization (ICAO). As a result, UAS communication and data link system have to provide links as shown in Table I and given below.

- Payload data (Electro-optical camera synthetic aperture radar and electronic sensor data) simplex transfer link,

- Duplex broadband UHF tactical communications audio radio channel;
- Duplex VHF airborne civilian ATC audio radio channel,

- Duplex UHF airborne broadband military ATC or tactical communications audio radio channel,

- Telemetry channel (Flight and payload control and status)

- A backup duplex telemetry channel.

- Duplex satellite communication channel (In the design of SATCOM capability),

- Duplex relay channel for BLOS operations.

\section{FREQUENCY BAND ALLOCATION}

UAS communication and data links require narrow bandwidth allocation for voice, telemetry and $\mathrm{C} 2$ and, wide bandwidth allocation for payload data as shown in Table II. As a kind of narrow band, UHF is used in LOS data link communications, as for VHF and HF, they are used in low throughput communications such as flight control, telemetry, voice etc. Wide band frequencies (L, S, C, X, Ku, K, and Ka) are used for high throughput communication. Wide band frequencies has some technical and operational pros\&cons as shown in the Table III. In the next paragraph these advantages and disadvantages of frequency bands will be also explained.

There are several wide frequency bands utilized for conveying vast amount of data. As seen on the Tables I and II; $\mathrm{C}$ and $\mathrm{Ku}$ bands are commonly used for transferring payload data whereby high throughput is needed [8]. In addition to $\mathrm{C}$ and $\mathrm{Ku}$ bands, S, X, K, Ka bands can be used in wireless communication, UAS communication, data link systems and satellite systems. [3]-[5] Ku band has high speed capability and short wave length and thus fragile to path loss. On the other hand, it is affected very few from obstacles and propagate large amount of data. $\mathrm{K}$ band can send larger amount data than $\mathrm{Ku}$ band but, it is sensitive to environmental interferences. S and L bands have low speed data transfer capability but penetrate ground obstacles and use low power transmitters. $\mathrm{C}$ band has large size wave length and thus requires sizeable transmitters and receivers. $\mathrm{X}$ band frequencies are reserved for military purposes (e.g. radar frequencies, SATCOMs). Voice and telemetry requires frequencies in UHF, VHF and HF bands.

TABLE II: UAS COMMUNICATION/DATA LINKS AND AVAILABLE FREQUENCY BANDS [6]-[9]

\begin{tabular}{|c|c|c|c|c|c|}
\hline Link & Stations & $\begin{array}{l}\text { Comms. } \\
\text { Direction }\end{array}$ & Data & $\begin{array}{c}\text { Data Rate } \\
\text { Requirement }\end{array}$ & Frequency Band \\
\hline $\begin{array}{l}\text { Flight } \\
\text { Control }\end{array}$ & GCS-Autopilot & Uplink & $\mathrm{C} 2$ & Low Band $<30 \mathrm{~Kb} / \mathrm{s}$ & HF, VHF/UHF \\
\hline Task-Payload Control & GCS-Payload & Uplink & $\mathrm{C} 2$ & Low Band $<30 \mathrm{~Kb} / \mathrm{s}$ & HF, VHF/UHF \\
\hline $\begin{array}{l}\text { Flight } \\
\text { Status }\end{array}$ & Autopilot-GCS & Downlink & Telemetry & High Band $<1 \mathrm{Mb} / \mathrm{s}$ & VHF/UHF \\
\hline Task-Payload Data & Payload-GCS & Downlink & Telemetry/Video Data & Broadband $>1 \mathrm{Mb} / \mathrm{s}$ & $\mathrm{L}, \mathrm{S}, \mathrm{C}, \mathrm{X}, \mathrm{Ku}, \mathrm{K}, \mathrm{Ka}$ \\
\hline UA Flight Process & UA-ATC & Downlink & Telemetry & High Band $<1 \mathrm{Mb} / \mathrm{s}$ & VHF/UHF, L, S \\
\hline Reporting & UA-Traffic & Duplex & Telemetry & High Band $<1 \mathrm{Mb} / \mathrm{s}$ & VHF/UHF, L, S \\
\hline Traffic Coordination & GCS-ATC & Duplex & Text/Voice & Low Band $<30 \mathrm{~Kb} / \mathrm{s}$ & HF, VHF/UHF \\
\hline $\begin{array}{l}\text { Mission Task } \\
\text { Coordination }\end{array}$ & $\begin{array}{l}\text { GCS-Command } \\
\text { Post }\end{array}$ & Duplex & $\begin{array}{c}\text { Text/Voice/Video } \\
\text { Data }\end{array}$ & $\begin{array}{l}\text { Low Band }<30 \mathrm{~Kb} / \mathrm{s} \\
\text { Broadband }>1 \mathrm{Mb} / \mathrm{s}\end{array}$ & $\begin{array}{c}\mathrm{HF}, \mathrm{VHF} / \mathrm{UHF} \\
\mathrm{L}, \mathrm{S}, \mathrm{C}, \mathrm{X}, \mathrm{Ku}, \mathrm{K}, \mathrm{Ka}\end{array}$ \\
\hline
\end{tabular}


TABLE III: FREQUENCY BANDS ADV. /DISADVANTAGES [3], [5], [6]

\begin{tabular}{|c|c|c|}
\hline Bands & Frequency Interval & Advantages/Disadvantages \\
\hline $\mathrm{HF}$ & 3-30 MHz & - \\
\hline VHF & 30-300 MHz & - \\
\hline UHF & $300-1000 \mathrm{MHz}$ & - \\
\hline $\mathrm{L}$ & $\begin{array}{c}\text { 1-2GHz (General) } \\
\text { 950-1450 MHz (IEEE) }\end{array}$ & $\begin{array}{l}\text { *Low speed } \\
\text { *Penetration capability into } \\
\text { obstacles } \\
\text { *Low speed }\end{array}$ \\
\hline S & $2-4 \mathrm{GHz}$ & $\begin{array}{l}\text { *Penetration capability } \\
\text { through obstacles }\end{array}$ \\
\hline $\mathrm{C}$ & 4-8 GHz & $\begin{array}{l}\text { *Sizeable transmitter/ } \\
\text { receiver Requirement }\end{array}$ \\
\hline $\mathrm{X}$ & $8-12 \mathrm{GHz}$ & $\begin{array}{l}\text { *Used in military } \\
\text { applications }\end{array}$ \\
\hline $\mathrm{Ku}$ & $12-18 \mathrm{GHz}$ & $\begin{array}{l}\text { *High speed } \\
\text { *Low Propagation Losses }\end{array}$ \\
\hline K & $18-26.5 \mathrm{GHz}$ & $\begin{array}{l}\text { *High Throughput } \\
\text { *Vulnerable to interference }\end{array}$ \\
\hline $\mathrm{Ka}$ & 26.5-40 GHz & $\begin{array}{l}\text { *High Throughput } \\
* \text { *ulnerable to interference }\end{array}$ \\
\hline
\end{tabular}

\section{UAS DATA LINK AND COMMUNICATION SYSTEMS OPERATIONAL REQUIREMENTS}

UAS concept of operations dictates certain requirements specific to unmanned flight. These requirements contribute to provide reliable, robust, interoperable and adequate bandwidth capable communication system design. In this section these operational requirements that must be taken into consideration in the conceptual design, explained below.

\section{A. Interoperability}

UAs operate in the same operation area with manned aircrafts, warships and other UAs. Consequently, UAs should have ability to work with other elements of the same forces. This situation results interoperability requirement [10]. In NATO forces UAs data link systems have to use message formats and interfaces determined in the STANAG 4586 in order to provide interoperability [11]. As we mentioned above, UAs can support the network centric backbone, so that they can act as nodes that connects ships, aircrafts, ground elements etc. Execution of gateway task requires UAs to be interoperable with the aim of conveying centralized $\mathrm{C} 2$ data to the end nodes [12].

Interoperability is provided both using standardized hardware (e.g. communication interfaces) and software at the same time. Development phase of the interoperable communication system is not affordable, on the other hand this ability minimizes lifecycle costs and requirements of the systems, adapt systems to shifting threats and new technologies [8].

\section{B. Reliable Communication}

UAS data links must be fully available during the operation for the safe control of the aircraft. For this purpose, data link should meet the robustness requirements against environmental conditions and constraints such as atmospheric fading, path loss, interference etc. [13]. In order to increase network reliability, it had better to use especially redundant $\mathrm{C} 2$ and telemetry links [7]. Besides environmental effect, cyber-attacks conducted by enemy makes data and communication link vulnerable. Consequently, UAS links should be robust against cyber-attacks and environmental constraints in order to provide reliable communication [14].

\section{Real-Time Communication}

UAS payload data, especially visual data and command control data have time-critical information. Any latency or distortion on conveying visual data decreases information value and get UA payload control difficult. For instance, when payload operator tracks moving ground target manually via video camera, the operator needs real-time video to orient payload camera onto the target precisely. This requirement is paramount for the use of the weapon systems on the UA in order to increase precise hit probability.

\section{Adequate Bandwidth Allocation}

Flight safety requires real-time communication and available continuous bandwidth for UA. However, UAS share the same spectrum with civilian and military manned aircrafts and thus, in order to execute safe flight, UAS have to use reserved and protected frequencies [15]. In the same operation area lots of UA's carry out tasks whereby frequency interference may occur. During the Second Gulf Operation, pre-planned UA flights were cancelled due to the inadequate bandwidth [16]. For instance, the estimation of the U.S. DoD bandwidth requirement is Exabyte (1 billion $\mathrm{Gb})$ for the year 2015 [17]. Consequently, UAS communication links have to have available and adequate bandwidth so as to prevent interference.

\section{E. Adaptation to Air Traffic Systems}

UA shares the same air-traffic controlled airspace with other manned aircrafts and thus, in the design phase of UAS, legal issues and aviation rules should be taken into account. Regional and international aviation standards defined by organizations (European Aeronautical Safety Agency (EASA), ICAO etc.) require mutual radio links between UA, ATC and GCS as shown in Fig. 3 [18].

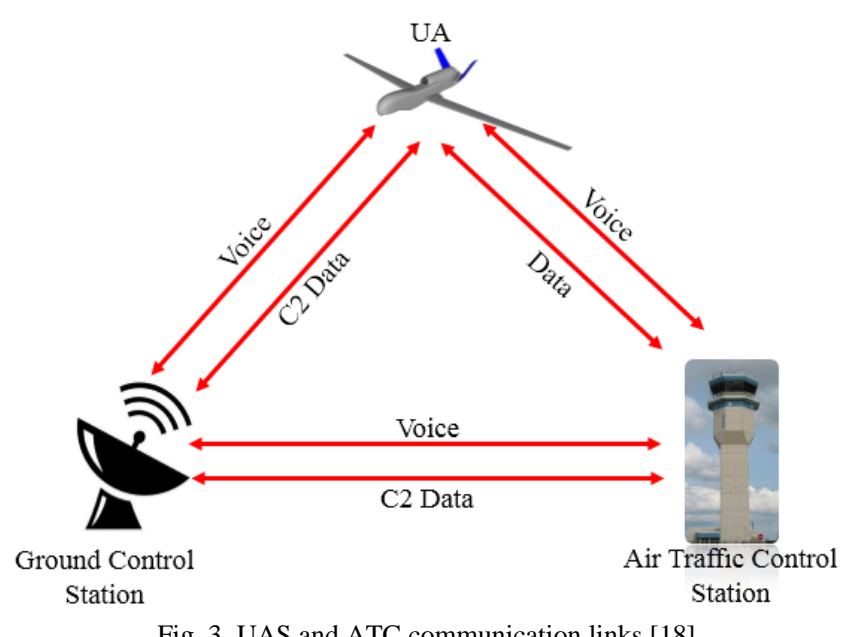

\section{F. Robustness to Deceptions}

UAS communications are vulnerable to enemy deceptions such as GPS spoofing, jamming etc. An enemy can send deceptive commands and take control of the aircraft. Then, deception can result with a crash, redirection to enemy airport or a recovery. In order to prevent deceptions, verification process is required and encrypted data must be used. Besides encrypted data communication, Direct-Sequence-Spread 
Spectrum (DSSS) or Frequency Hopping Spread Spectrum (FHSS, also called "Frequency Agile.") systems should be benefited in the system design [19]. In frequency agile systems, frequency is changed in random sequences and thus enemy jammer frequencies do not match with UAS frequencies. On the other hand, frequency agile systems have to be in coordination with other friendly systems in order to communicate in the same frequencies. So, all friendly terminals communicating each other have to have a synchronization. In DSSS systems, message to be conveyed divided into small pieces and each part of message is transmitted on different allocated part of the spectrum. Small message parts which are damaged by a jammer, can be recovered by a jam resistant verification signal. In conclusion, this DSSS process makes the communication link robust to jammers.

\section{G. Low Probability of Intercept (LPI)}

Enemy Electronic Support Measurement (ESM) systems try to detect both GCS and UA position with the use of propagated signals from this stations. Since, UA is a moving and GCS is stationary target, ESM systems have high probability to detect GCS rather than UAV. This situation makes GCS a potential target for enemy missiles and artillery guns. So, uplink transmitted from GCS should have ability of LPI. On the other hand modern smart missile and radar systems can easily detect moving targets and thus UA also should have the same ability. In order to provide LPI capability, DSSS, FHSS, dynamic power management, directional transmission and low duty cycle methods are should be taken into consideration [19].

\section{CONCLUSION}

It has the vital importance to define system requirements without any short and fault in order to provide both the project and the mission success [2]. Otherwise, as seen in the UAS case; enemies can take control of the UA, record intelligence data remotely and detect the position of the systems on the ground, bandwidth shortage can make it harder to execute adequate UAS operations. These incidents can interrupt the success of the mission. For this reason, it is significant to define requirements for data link and communication systems of UAS. In conclusion, the operational requirements of UAS data link and communication systems are determined considering the CONOPS. In this context, operational requirements written below:

- Interoperability,

- Low probability of intercept,

- Reliable communication,

- Robustness to deception and jamming,

- Real-time communication,

- Adaptation to air traffic control,

- Beyond Line of Sight communication,

- Adequate bandwidth allocation

are defined and explained in detail. Open source UAS technical documents, vendor's datasheets and website show that, nearly all UAS models have met these requirements particularly. Especially wide band communication capability, interoperability, near real time communication capability, adaptation to ATC, reliable communication and BLOS requirements have been fully met in strategic/operative UAS models such as Heron, ANKA-S, Reaper, Predator and Global Hawk etc. While BLOS communication is conducted via SATCOM in these models, as for in tactical UAS such as Bayraktar, Fire Scout, Pioneer etc., BLOS communication is conducted via relay UAS nodes. [11], [20], [21].

Defining these requirements are significant for the design phase of the systems for the purpose of building technical infrastructure and these requirements are also important for military operations success. It's very difficult to integrate new requirements after the conceptual design phase, especially in the production process and the military utilization phase.

Each operational requirement brings the necessity of research and development on new technologies. These requirements also will be research topics for academic future works. These requirements brings new research areas for the academic personnel who work on UAS

In conclusion, defining these requirements, as we mentioned the importance and necessity of it above, will contribute in meeting the user's needs, research of RND and academic personnel, knowledge and experience of the industry.

\section{REFERENCES}

[1] R. Austin, Unmanned Aircraft Systems; UAVs Destgn, Development and Deployment, John Wiley \& Sons Ltd. Publication, 2010, ch. 9.

[2] B. S. Blanchard and W. J. Fabrycky, Systems Engineering and Analysis, 3rd ed. Prentice Hall Publication, 1997, ch. 1, p. 26.

[3] The International Remotely Piloted System Information Source Market Overview: UAV Communication Links. [Online]. Available: http://uvs-info.com/

[4] H. R. Saeedipour, M. A. M. Said, and P. Sathyanarayana, "Data link functions and attributes of an Unmanned Aerial Vehicle (UAV) system using both ground station and small satellite," presented at the 5th IAA Symposium on Small Satellites for Earth Observation, Berlin, Germany, 2005.

[5] S. G. Gupta, M. M. Ghonge, and P. M. Jawandhiya, "Review of Unmanned Aircraft System (UAS)," International Journal of Advanced Research in Computer Engineering \& Technology, vol. 2, issue 4, pp. 1646-1658, April 2013.

[6] R. Jain and F. L. Templin, "Wireless datalink for unmanned aircraft systems: Requirements, challenges and design ideas," presented at the American Institute of Aeronautics and Astronautics Infotech Aerospace, St. Louis, Missouri, USA, 2011.

[7] Tellumat Defence Datasheet, Unmanned Aerial Systems Subsystems, Cape Town, S.A.: Tellumat (Pty) Ltd., 2011, issue 1.

[8] Unmanned Systems Integrated Roadmap 2009-2034, Department of Defense, Washington, DC, April 2009.

[9] F. Dimc and T. Magister, "Mini UAV communication Link systems," Ljubljana University, 2007.

[10] J. Gertler, "U.S. Unmanned Aerial Systems," Congressional Research Service (CRS), Report for Congress, January 3, 2012.

[11] Standard Interfaces of UAV Control System (UCS) for NATO UAV Interoperability, NATO Standardization Agency (NSA) Standardization Agreement (STANAG) 4586, February 2007.

[12] Unmanned Systems Roadmap 2005-2030, Department of Defense, Washington, DC, August 2005.

[13] S. Baiotti, G. L. Scazzola, G. Battaini, and E. Crovari, "Advances in UAV data links: Analysis of requirement evolution and implications on future equipment," presented at the RTO SCI Symposium on Warfare Automation: Procedures and Techniques for Unmanned Vehicles, Ankara, Turkey, April 26-28, 1999.

[14] K. Hartmann and C. Steup, "The vulnerability of UAVs to cyber-attacks - An approach to the risk assessment," in Proc. 5th International Conference on Cyber Conflict, 2013, pp. 95-118.

[15] S. Henriksen, "Unmanned aircraft system control and ATC communications bandwidth requirements," National Aeronautics and Space Administration (NASA), Glenn Research Center, Cleveland, Ohio, Feb. 2008 
[16] The International Remotely Piloted System Information Source. [Online]. Available: http://uvs-info.com/

[17] K. A. Gambold, "Unmanned aircraft system access to national airspace," Technical and Air Safety Committee, GAPAN North America, Nov. 2011.

[18] The International Remotely Piloted System Information Source. Certification \& Legislation \& Related Topics: Frequency spectrum requirements. [Online]. Available: http://uvs-info.com/

[19] E. Torun, "UAV requirements and design consideration," presented at the RTO SCI Symposium on Warfare Automation: Procedures and Techniques for Unmanned Vehicles, Ankara, Turkey, 1999.

[20] Turkish Aerospace Industry (TAI). [Online]. Available: http://www.tai.com.tr

[21] Bayka http://www.baykarmakina.com.tr

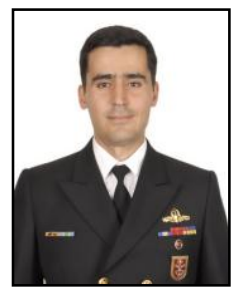

Hüseyin Okcu was born in Kırıkale, Turkey in 1981. He received his B.Sc. degree in electrical and electronic engineering from the Turkish Naval Academy, İstanbul, Turkey, in 2005, and the M.Sc. degree in computer engineering from the Naval Science and Engineering Institute, İstanbul, Turkey in 2012.

He served for four years in the Turkish Navy Frigates as an weapon electronic officer, and two years in the Turkish Naval Academy as both instructor and company officer. He has been studying in the Turkish Naval War College in İstanbul since 2014. His previous research interests are machine learning, wireless sensor networks, modelling and simulations. $\mathrm{He}$ is currently studying on Unmanned Aircraft Systems in the Turkish Naval War College. 
Wireless Sensor Network Technology 
